J. Neurol. Neurosurg. Psychiat., 1954, 17, 267.

\title{
THE EFFECT OF TEMPORAL LOBECTOMY UPON TWO CASES OF AN UNUSUAL FORM OF MENTAL DEFICIENCY
}

\author{
BY
}

\author{
D. W. LIDDELL and D. W. C. NORTHFIELD
}

From Runwell Hospital, Wickford, Essex

In 1898, when giving the final particulars and the necropsy findings of a case of epilepsy which fully exemplified dreamy states and automatisms, Hughlings Jackson (1931a) wrote that there were postepileptic actions " of a kind which in a man fully himself would be criminal ". But another 25 years were to elapse before Penfield began his studies on brain-scars (Penfield and Erickson, 1941) which were eventually to secure for surgery a place in the treatment of epilepsy. At first the operations were restricted to those patients resistant to medical treatment in whom there was conclusive evidence of a focal scar, usually the result of a head injury. With the introduction of electrical recording devices, the field of surgery has been extended so that now the indications for operation comprise the recognition of an appropriate seizure pattern and the electroencephalographic evidence of a focal discharge in a patient resistant to medical treatment. The recognition of an appropriate seizure pattern is still of the utmost importance, notwithstanding the great value of abnormal electrical records. It is doubtful whether the wide variety of seizure manifestations has ever been more accurately and more fully described than by Hughlings Jackson and also by Gowers (1892) and this applies in particular to that variety of seizure which is now often termed temporal lobe epilepsy. In recent years interest has been focused particularly on the forms of mental disorder which may arise in persons suffering from this type of epilepsy. As in the passage quoted from Hughlings Jackson's writings, these disorders may be episodic and strictly related to a fit. But in other patients it seems that the mental disorder may persist and worsen without remission, rendering the subject unable to retain his place in the community. Such deterioration may not necessarily be permanent if the discharging and apparently disorganizing focus can be detected and removed, as the following two cases exemplify.

\section{Case Histories}

Case 1.-M. G., aged 18 years, was referred to Runwell Hospital from the Royal Eastern Counties Hospital because of bouts of violent uncontrollable behaviour and repeated attempts to abscond. He was the seventh child of healthy working-class parents. There is no family history of epilepsy. His birth was normal and he was breast fed for nine months. He began to walk and talk at about 14 months. As a child he was placid but active, easily managed, and there were no difficulties in toilet training.

At the age of 7 years he fell out of a tree and was momentarily unconscious. Then 15 months later he began to have fits which initially consisted of feeling giddy followed by a momentary lapse of consciousness but no falling, and during this period he would raise both arms above his head. This would occur up to seven times a day. Associated with this, a change in his personality occurred, for at school he started to become mischievous and "played-up" his teachers. Until this time school reports show that he was an average scholar. About 10 months after the onset of these minor fits, the character of his fits changed. They became more severe and falling and convulsive movements occurred. These turns were preceded by a well marked aura lasting up to two minutes, which enabled him to warn people near him that a fit was pending. The aura consisted of a fully formed musical tune which he felt he had heard a long time ago, but occasionally it consisted of the sound of bells, accompanied by giddiness. He was never able to describe the tune or to remember it after the attack. There were no known precipitating factors. Occasionally, by hard concentration, he was able to abort the fit. Following the aura, the head and trunk would turn to the right and the right arm would flex before the onset of clonic movements in all four limbs. Several such fits were observed in this hospital. The onset of these fits was accompanied by a rapid deterioration in his behaviour, and at the age of 11 years he was admitted to an epileptic colony for 16 months. After this time his removal was requested because of his antisocial behaviour and frequent attempts to abscond. His I.Q. was 81 (revised Stanford-Binet scale form $L$ ) at this time. There followed a period at home in which his behaviour 
deteriorated still further and fits occurred unchecked by medical treatment ; he was certified as a mental defective at the age of 14 years and admitted to the Royal Eastern Counties Hospital. While in this hospital he had episodes of bizarre behaviour in which he would climb on lockers and wander off without subsequent recollection and if restrained would become violent and destructive.

Physical examination at Runwell Hospital revealed a healthy youth who showed a mild right hemiatrophy with a right involuntary facial weakness, especially when he smiled. His speech was slurred and delivered in a whining, ingratiating way. There was also a right extensor plantar response. Mental examination revealed a rather simple youth who smiled readily in a fatuous way. He constantly importuned everyone for cigarettes or food and at other times demanded that they should listen to simple rhymes he had made up. Anyone would act as a trigger for him to demand in a whining tone, " Give us a fag, sir". This constant whining patter was a source of annoyance to other patients as was the repetition of jingling rhymes.

"None of these won't let me give him a saccharine

Because they think it might make him dream

And if he dream

He might turn green

So he don't look clean

And so he might never see the Queen."

His emotional behaviour in every way was like that of a child of 7, for he sulked readily. If no one listened to the verses he became pettishly annoyed. Slight praise would send him jumping for joy. He entertained vaguely hostile ideas against the nursing staff who, he felt, watched him unnecessarily closely and curtailed his activities. He was inquisitive, constantly interfered with people, and never seemed to learn from his rebuffs. He was correctly orientated, fairly well informed about current events, and performed serial sevens promptly and accurately. For long periods he would occupy himself painting designs with great thoroughness. He was able to write a few simple words, but spelling was poor. His vocabulary was surprisingly good. Psychometric examination gave him on the Wechsler-Bellevue a verbal I.Q. of 63 , a performance I.Q. of 48 , making a full I.Q. of 51. On Raven's Progressive Matrices he obtained 29 correct solutions, being Grade IV. An air encephalogram revealed dilatation of the inferior horn of the left lateral ventricle. Electroencephalographic examination of August 6,1952, revealed considerable high voltage dysrhythmic activity in the delta and theta groups from all areas, but greater on the left side. Fronto-temporally the abnormality was very much greater on the left side than the right and was focal over the left anterior temporal region (Fig. 1). The delta activity here was frequently associated with both slow and fast spikes which were likewise focal. Posteriorly an alpha rhythm at $9 \mathrm{c} / \mathrm{s}$. was discernible, responding to opening the eyes.

The above behaviour was frequently punctuated by that of a different sort in which he became excessively hostile, withdrawn from people and refusing food. The

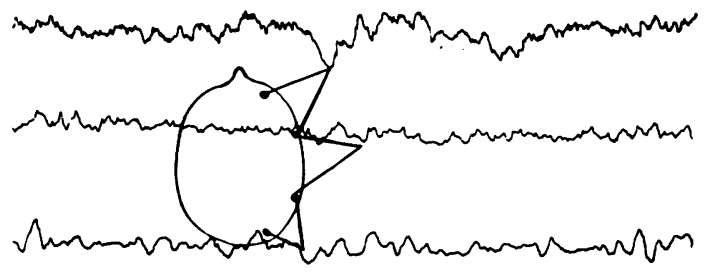

$\lceil 50 \mu v \stackrel{\text { ISECOND }}{ }$

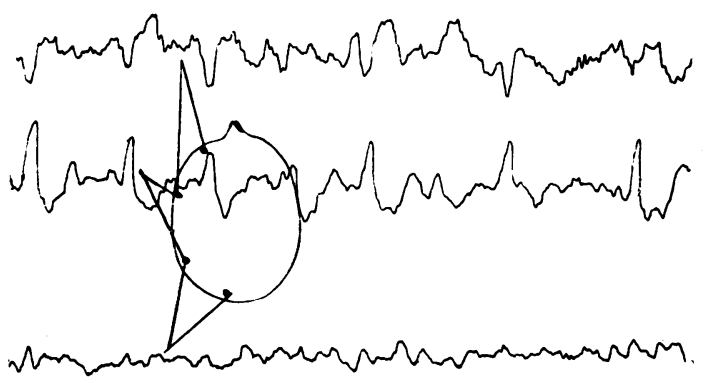

FIG. 1.-Case 1 : E.E.G. reveals left anterior temporal sharp wave focus.

slightest provocation would send him into a violently destructive rage. During this period, which would last up to 48 hours, he was confused and disorientated. He had obvious difficulty in finding words and when attempting to speak was unable to give any clear account of himself. His mouth would frequently move but no sound emerged. Afterwards he had little or no memory for these periods. During one such turn his E.E.G. revealed continuous high voltage $2 \frac{1}{2} \mathrm{c} / \mathrm{s}$. and $5 \mathrm{c} / \mathrm{s}$. activity over the whole cortex (Fig. 2). These episodes were considered to be prolonged automatisms.

On December 3, 1952, left temporal lobectomy was performed, as the usual anti-epileptic medication in various combinations seemed in no way to control either his fits or behaviour, for even on heavy medication he was having up to 24 fits per month, often in bouts of three or four per day, in addition to his periods of prolonged automatism which might occur weekly.

The operation was carried out under local anaesthesia, following premedication with morphia, a minimal dose of pentothal being administered for breaking the bone flap (Dr. Waterfall). The surface of the brain was of normal appearance. Unfortunately, electrocorticography as planned could not be undertaken. The inferior extremity of the precentral gyrus was identified by electrical stimulation (sine-wave, 2 volts for two seconds) but no responses could be evoked from the exposed surface of the temporal lobe. A formal partial lobectomy was carried out, the posterior line of section traversing the lobe approximately along the vein of Labbé, the plane of its upper (Sylvian) limit lying $5 \mathrm{~cm}$. and its inferior limit $7 \mathrm{~cm}$., respectively, behind the tip of the temporal pole. The resection included the uncus, and as much of the hippocampal gyrus as lay anterior to the plane of the section. The insula was left intact. 


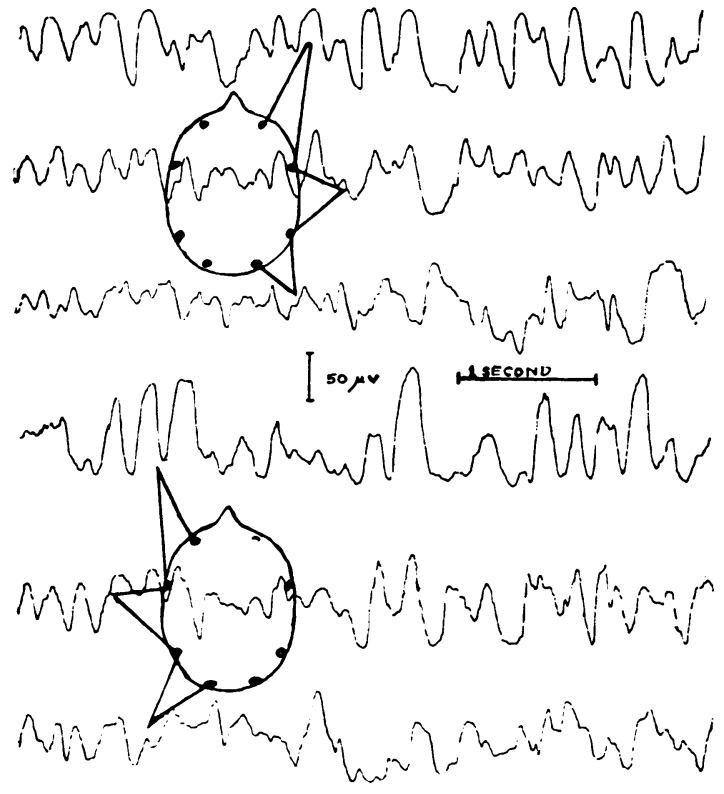

FIG. 2.-Case 1: electroencephalogram taken during a period of prolonged automatism showing diffuse high voltage at $2 \frac{1}{2} \mathrm{c} / \mathrm{s}$. and $5 \mathrm{c} / \mathrm{s}$. activity.

Pathology.-Dr. J. A. N. Corsellis reported as follows : The weight of the fixed specimen ( $10 \%$ formalin) was $32 \mathrm{~g}$. It measured $5 \mathrm{~cm}$. antero-posteriorly and $5 \mathrm{~cm}$. lateromedially (superior temporal gyrus to hippocampus).

The specimen consisted anteriorly of the intact temporal pole. More posteriorly it included the three temporal gyri (the upper surface of the superior temporal was largely missing), the fusiform, and the hippocampal gyri. Its medial border was formed by part of the amygdaloid nucleus, the wall of the inferior horn, and a small part of the hippocampal formation (Fig. 3).

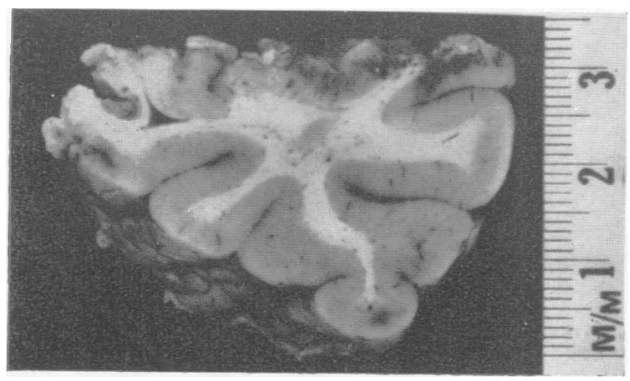

FIG. 3.-The naked-eye appearance of the specimen cut coronally $2.5 \mathrm{~cm}$. posterior to the temporal pole in Case 1.

Apart from much congestion and many small areas of recent haemorrhage no abnormality was seen either on the surface or after cutting the brain.
The specimen was cut into three coronal blocks and sections were examined from each level. The established abnormal histological findings, i.e., present before operation, were those of a moderately severe sub-pial glial fibrosis extending down into the second cortical layer (Fig. 4). There was also a marked increase of astrocytes in the white matter and a fine glial fibrosis. A fragment of the hippocampal formation was present but no dentate gyrus. This fragment included a part of the Sommer section ( $\mathrm{H} 1)$ where the layer of pyramidal nerve cells was present but, as elsewhere in the cortex, many of these were shrunken and darkly stained, and related probably to the operation. The glial changes, although patchy, were of about equal severity in all areas examined and no localized lesion of any kind was found.

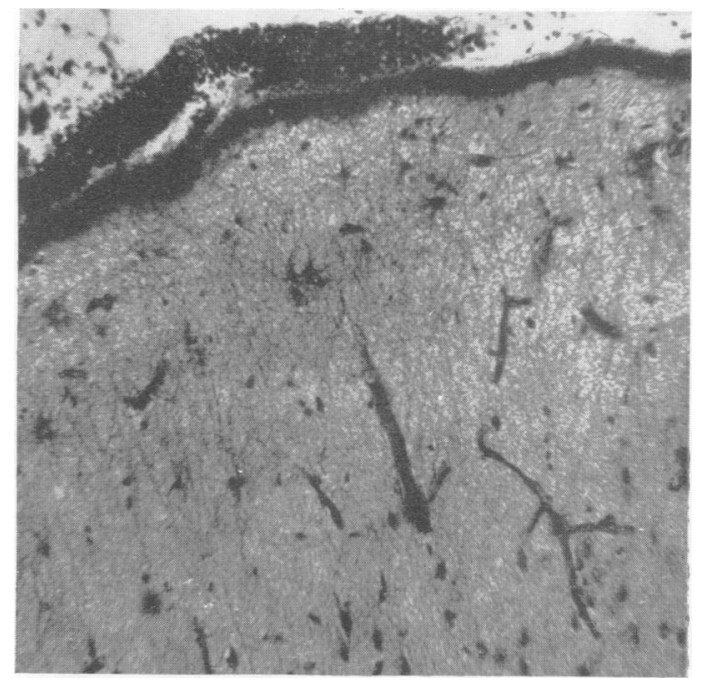

FIG. 4.-A fairly dense sub-pial glial fibrosis, also penetrating into the cortex in Case 1. Mallory's P.T.A.H. $\times 184$.

Post-operative Course.-There have been no fits since the operation 17 months ago. Immediately after operation the patient was hypersomnolent and it was impossible to arouse him by the usual method of shaking. $\mathrm{He}$ would wake at meal times but was fed with difficulty. However, after 14 days this gradually passed off. When he was up and about a noticeable change in his behaviour was apparent ; he was quieter and more contented. He lost all his previous persistent importuning attitudes and was able to attend occupational therapy where he worked well. In addition he started to learn to read, which previously he was unable to do except for simple words. All his cravings for cigarettes and food vanished and he rapidly lost his habit of repeating childish rhymes and quips. Speech, however, lost its natural cadence and each word was delivered with the same emphasis. He became alert, well behaved, and began to take a pride in his appearance. Eight months ago he was let 
out on licence and since then has been diligent at home. His mother is delighted with the change in him. Of great interest is that following operation he has grown rapidly in height. His mood has changed from that of a child to one of quiet stolidity. He occupies himself for long periods alone and is planning to become a gardener. His I.Q. has also shown a steady improvement (see Table). This case shows clearly how profoundly the

TABLE

PROGRESSIVE IMPROVEMENT OF INTELLECTUAL PERFORMANCE IN CASE 1

\begin{tabular}{|c|c|c|c|}
\hline Test & $\begin{array}{c}29.11 .52 \\
\text { (before } \\
\text { operation) }\end{array}$ & 2.1 .53 & 8.2 .54 \\
\hline $\begin{array}{l}\text { Wechsler-Bellevue Scale : } \\
\text { Verbal I.Q. } \\
\text { Performance I.Q. }\end{array} \quad \ldots$ & $\begin{array}{l}63 \\
48 \\
51 \\
29 \text { correct } \\
\quad \text { results } \\
\text { Grade IV }\end{array}$ & $\begin{array}{l}73 \\
65 \\
66 \\
41 \text { correct } \\
\quad \text { results } \\
\text { Grade III }\end{array}$ & $\begin{array}{l}79 \\
74 \\
75 \\
43 \text { correct } \\
\text { results } \\
\text { Grade III }\end{array}$ \\
\hline
\end{tabular}

I.Q. will drop in epilepsy occurring early in life, for we have an early intelligence test obtained while he was in an epileptic colony when his behaviour and learning ability had already begun to deteriorate. It was then 81 . Over the next few years his intelligence dropped progressively, until before operation it was 51 . Since then it has shown a continual rise. The Progressive Matrices, which have perhaps the highest " $g$ " saturation, show that his intelligence is now average. The WechslerBellevue test does not to date confirm this great improvement, but the test is no doubt dependent on education and learning as well as intelligence.

The E.E.G. a month after operation revealed a right temporal focus of sharp waves by phase reversal, but this had vanished three weeks later when the record was normal except for some flattening and low-voltage slow activity over the left temporal region (Fig. 5). However, 13 months later the E.E.G. revealed a right slow frequency posterior temporal focus of 5 to $7 \mathrm{c} / \mathrm{s}$. activity which responded rapidly to opening the eyes (Fig. 6). This type of response has been described by Hill (1952) as a maturational phenomenon occurring normally in children and only of pathological significance if persisting into adult life. The great interest in this is that not only has the focus appeared but its appearance has coincided with a rapid increase in physical growth and a rapid maturation of his personality from that of a child to one of an adult. Its presence may well indicate the possibility of still further improvement in this youth. It would seem that a frequently discharging lesion of an area of the brain has, as Krynauw (1950) suggested, profoundly altered the function of normal brain. Its removal has allowed maturation to proceed and accompany-

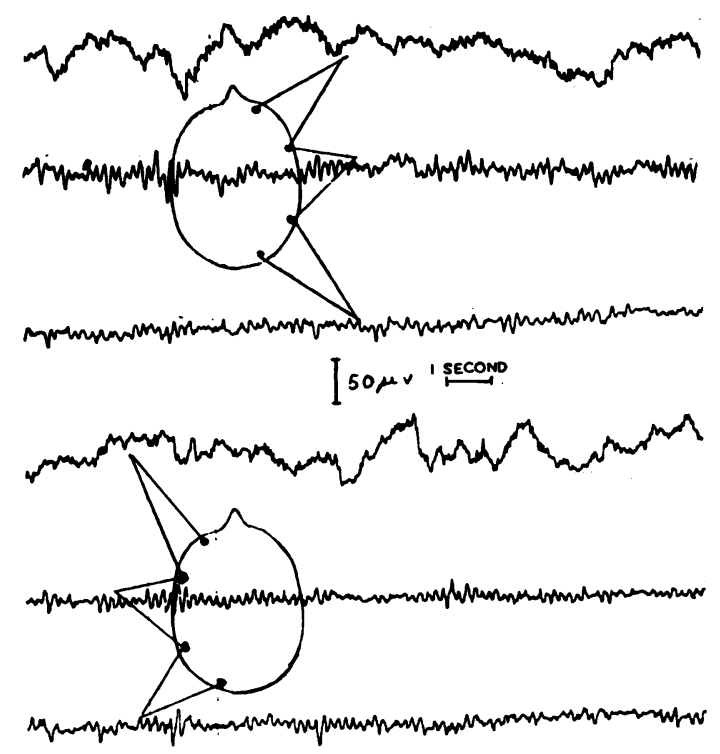

FIG. 5.-Case 1 : E.E.G. post-operatively appearing normal arart from low-voltage slow activity over left temporal region.

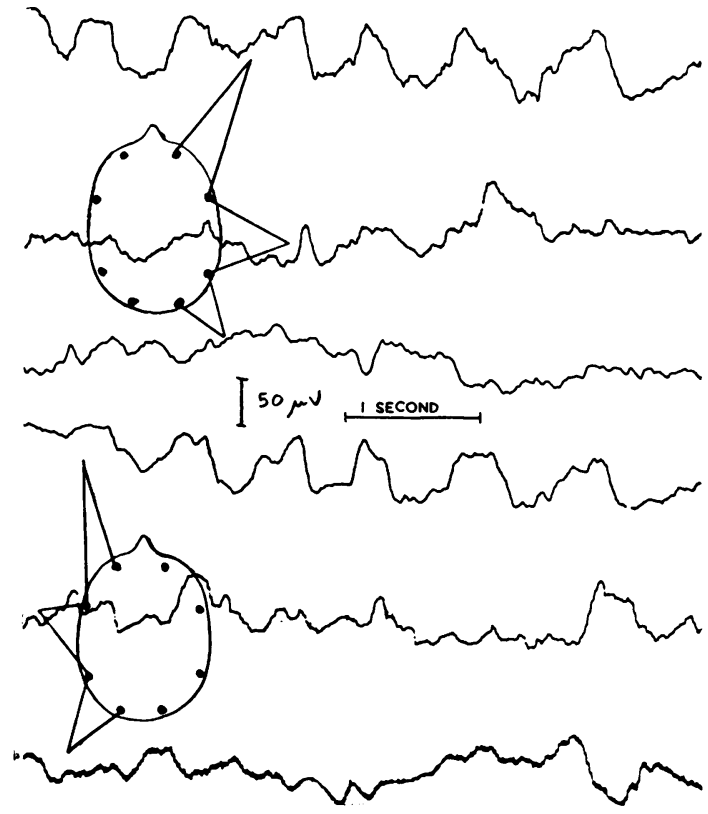

FIG. 6.-Case 1 : E.E.G. 15 months post-operatively showing right posterior temporal slow wave focus responding to opening of the eyes. 
ing this there has been a generalized increase of active growth affecting body and personality.

The hypersomnolence is an unusual feature. Gibbs, Gibbs, and Fuster (1948) claim that it is common amongst patients with temporal lobe epilepsy, but this has not been our experience. However, Poirier (1952) in attempting to obtain Klüver and Bucy's syndrome in monkeys by producing minimal bilateral temporal lobe lesions, obtained instead hypersomnolence in monkey No. 5 . This monkey was in a state resembling those asleep following hypothalamic lesions. Microscopic studies, however, showed that the lesions did not involve the hypothalamus, but chiefly the medial and basal portions of the temporal lobe, especially in the amygdaloid area.

Case 2.-H. G. R., aged 20 years, was referred to Runwell Hospital from the Royal Eastern Counties Hospital because of aggressive outbursts and degraded behaviour. The patient was the fourth sibling of seven children, born of working-class parents. There is no family history of epilepsy but a maternal great-aunt was an imbecile. His birth was normal and he was breast fed. He was always a contented child, walked at 11 months and began to talk a few months later. At the age of 5 years he began to have temper tantrums and bit his nails. He attended school until the age of 15 years. Reports state that he was rather backward but could do better if he tried. However, he learnt to read and write. On leaving school he was apprenticed to a carpenter and was apparently a willing worker and well liked. He was particularly attached to his mother and frequently bought her little presents. He was polite and well mannered. He used to save his money and only smoked occasionally.

When about $15 !$ years of age, he sustained a head injury and four months after this had his first "black-out". He would suddenly stare vacantly ahead for a minute and afterwards became confused and restless. When he had returned to normal he would remember nothing of the episode. Once started, the fits rapidly increased in number in spite of medication. Because of the repeated attacks of confusion, he was kept in the house. However, he did not understand the reason and resented the confinement and became moody and difficult. At this period he developed an intense craving for cigarettes and started to look everywhere for them. Because of this craving he began to steal small sums of money and whenever he managed to get out of the house he would also steal from neighbours and shopkeepers in order to satisfy his desire for a smoke. Eventually, repeated larceny brought him to court at the age of 16 years, and from a remand home he was transferred to a mental hospital as a voluntary patient, but because of frequent wandering he was certified as a mental defective. Major fits are said to have occurred but no description was obtained.

In the Royal Eastern Counties Hospital his turns continued unabated and a striking deterioration in his behaviour resulted. He was described as noisy and garrulous, filthy in his habits, even eating his own excreta. He had an intense craving for cigarettes. He masturbated freely. At times he became impulsive and violent towards other patients. His I.Q. in 1950 was 63 on Terman-Merrill form $L$.

While in Runwell Hospital, before operation, he had numerous turns in which he would go stiff, stare into space for half a minute and then become more confused than usual for 10 minutes. There was no chance of missing a fit, for he always ran to a nurse pressing his own hand against his head and moaning. Following lobectomy he was able to elaborate on his aura ; it was an intense, agonizing pain of sudden onset in the centre of his head. He further added that if the aura occurred at night it always did so at the end of a particular dream, in which he finds himself snatching his sister's handbag out of her hand and then running off. As he ran away the severe headache occurred. During the day no thought or idea was associated with the cephalgia. A constant form of automatism was rummaging through the nearest person's pockets, or banging his head against the nearest wall at the beginning of his confusion.

Physical examination revealed a healthy youth who looked much younger than his years. Speech was slurred, probably due to barbiturates, but there was no nystagmus. Apart from gross unsteadiness while standing on the left leg, there were no abnormal physical signs in the central nervous system.

Mental examination revealed a confused youth who could give little account of himself. His voice was loud and whining and his conversation was broken continuously by demands for cigarettes. He was unable to pursue any topic, for after a few words a fresh demand for cigarettes would arise and he would forget what he had said previously. In addition, long pauses would occur, and often the same word would be repeated a number of times. He frequently took hold of people's hands and put them in his mouth. In fact most interviews would begin with this procedure and it appeared to be his method of identification. However, he appeared to obtain great pleasure by formulating very simple, childish conundrums and was delighted if he caught anyone out. He was excessively inquisitive and wanted to pry into everyone's acts ; whatever they were doing he wanted to do. Repeated rebuffs had no effect on him and often he had to be isolated to protect him from more impulsive patients who became more than irate as he fingered all their belongings. He was never silent, but kept up a constant loud, whining speech. He was never still, would wander all over the wards trying to pilfer cigarettes, and never sat or occupied himself. His habits were degraded. All objects were correctly named. He was able to read a little and also write a few simple words. He was able to repeat only four digits forward and none backward, and his grasp of general knowledge was equally poor.

Psychometric testing gave him on the WechslerBellevue test a performance I.Q. of 63. An air encephalogram revealed normal ventricles. An E.E.G. revealed high voltage, continuous slow activity at 1 to $5 \mathrm{c} / \mathrm{s}$. 


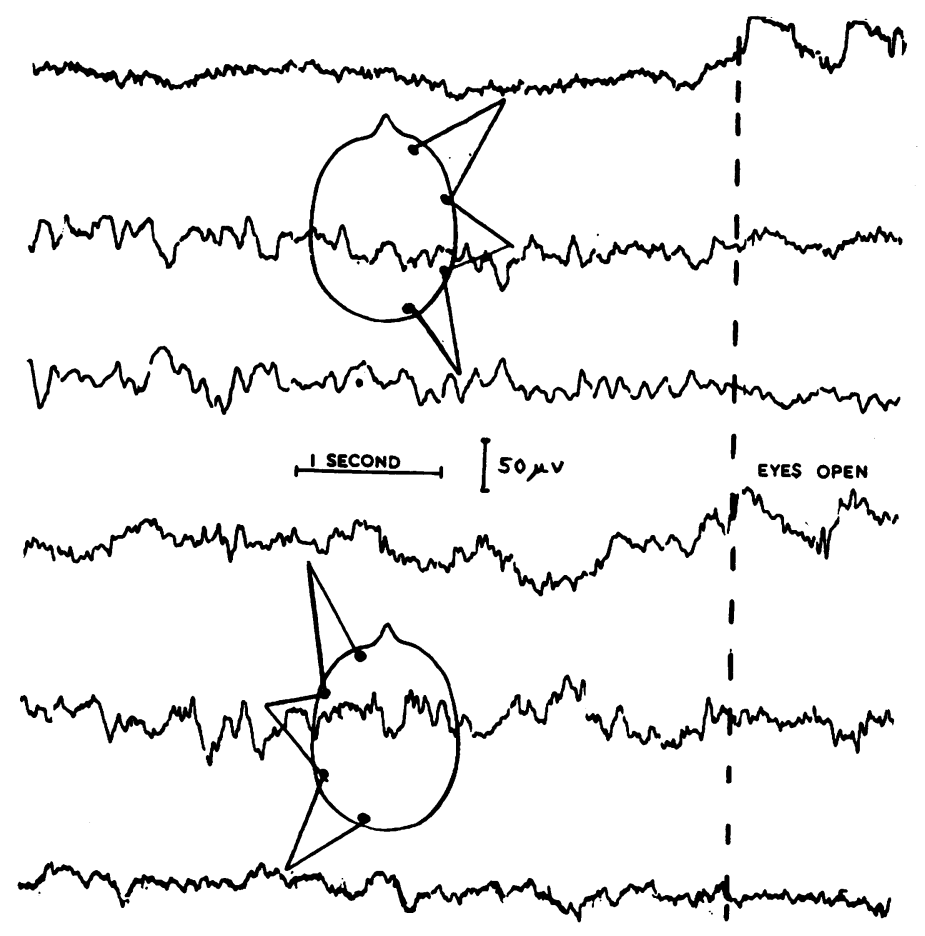

FIG. 7.-Case 2 : E.E.G. before operation showing generalized mixed slow activity. tumour. The insula was preserved. Electrocorticographic records taken at the end of the operation revealed a marked reduction of all activity from the surrounding brain, there being only a very few low-voltage random spikes.

Pathology.-Dr. J. A. N. Corsellis reported as follows: The weight of the fixed specimen was $45 \mathrm{~g}$. It measured $5 \mathrm{~cm}$. antero-posteriorly and $6 \mathrm{~cm}$. latero-medially.

The anatomical limits of the specimen generally resembled those in the first case although only the infero-lateral edge of the inferior horn was present and no hippocampal formation or amygdaloid nucleus was identified.

No macroscopic abnormality was seen (Fig. 9) but the fixed tissue felt unusually tough on section.

Glial changes similar in distribution and intensity to those in Case 1 were present. In the white matter the gliosis was more marked. No localized lesion was found.

Post-operative Course.-Since the operation four months ago there have been no fits. For the first week the patient maintained the same childish attitude to life, and then started to improve. The improvement has been

which was greater over the right cerebral hemisphere (Fig. 7). Sphenoidal electrodes revealed an almost continuously firing right basal sharp wave focus (Fig. 8) and this was frequently associated with firing from the left base which appeared to be secondary to that on the right. Throughout, the cortical activity remained unchanged at $1 \frac{1}{2}$ to $3 \mathrm{c} / \mathrm{s}$.

On December 17, 1953, right temporal lobectomy was performed under light general anaesthesia (gas, oxygen, and pentothal, Dr. Stride). The surface of the brain appeared normal. Electrocorticography revealed a considerable abnormality, particularly from the anterior part of the lobe, and there was evidence that the discharges were arising anteriorly-from an area hidden under the bone-and spreading backwards. The record included high voltage delta and theta activity, random spikes and sharp waves, and at times runs of spikes at beta frequency. Cortical stimulation (sine-wave, 2 and 4 volts for two seconds) produced no change in the electrocorticograph. Formal lobectomy was carried out, the posterior plane of resection lying $5 \mathrm{~cm}$. behind the tip of the temporal pole, and including the uncus and as much of the hippocampal gyrus as lay anterior to that plane. The brain tissue appeared tougher than normal, and this was particularly the case in respect of the uncus and hippocampal gyrus, where the leptomeninges were also thickened and tough. The medial part of the uncus extended further over the free edge of the tentorium than is usual in a case with no

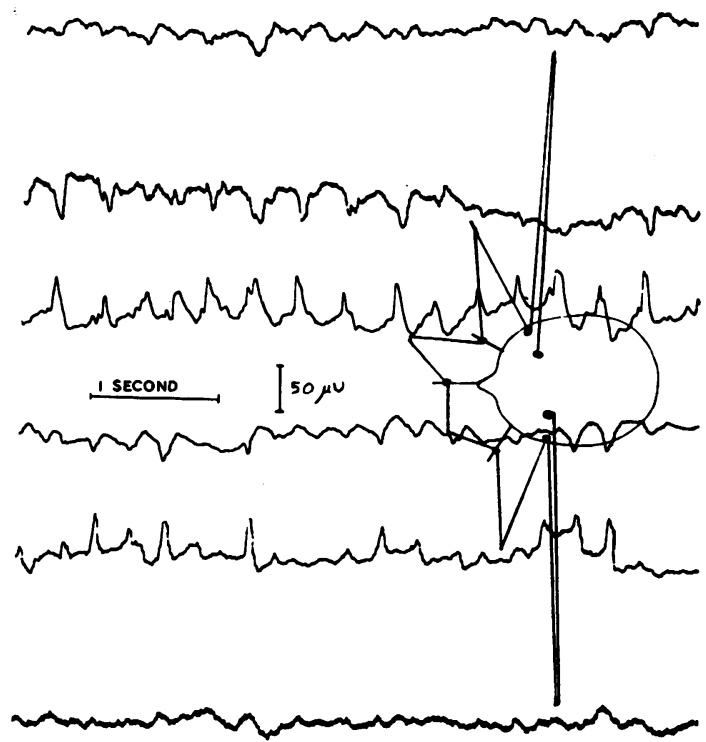

FIG. 8.-Case 2 : sphenoidal leads taken at the same time as Fig. 5 showing well marked bilateral, frequently firing foci, right greater than left. 


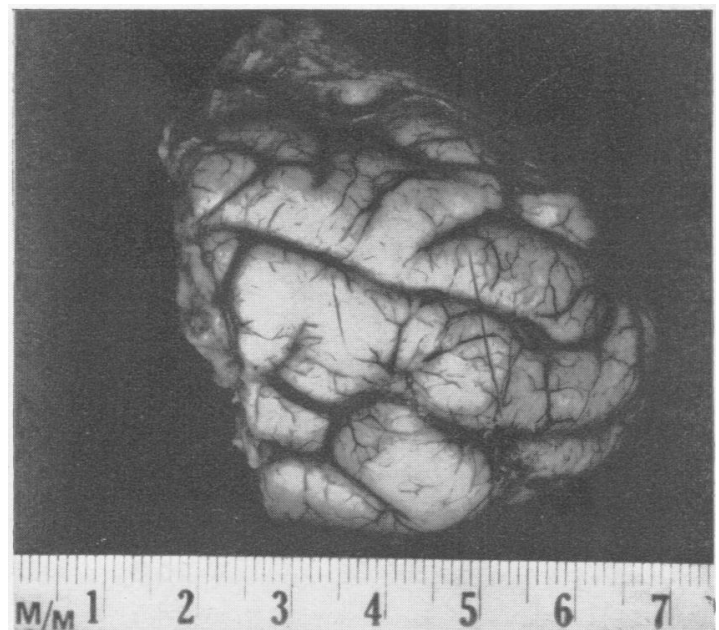

FIG. 9.-Lateral view of the portion of temporal lobe removed with the superior temporal gyrus uppermost and the pole to the right in Case 2.

rapid. He is now able to hold a conversation without losing his train of thought. Perseveration of ideas and words has vanished. $\mathrm{He}$ is no longer meddlesome, keeps very much to himself, and is able to occupy himself with simple woodwork. He is polite and takes some pride in his appearance. His voice, however, is monotonous and has lost its normal cadence. $\mathrm{He}$ is able to name objects correctly and read and write to a small extent. On confrontation there is no visual field defect. Apart from some low-voltage theta activity at 4 to $6 \mathrm{c} / \mathrm{s}$. in the right temporal region, the E.E.G. taken one month post-operatively shows a normal record (Fig. 10). At about this time he was taken round the hospital to the wards in which he had been first, but had no recollection of them, the nurses, or the patients. He could give no account of his time in hospital and did not know how long he had been there.

Six weeks after operation he spontaneously remarked that one of us (D. W. L.) was now of normal size. He was able to elaborate that when he first started to remember things after the operation, and to understand his whereabouts, he was surprised to find that everyone was excessively tall, and the outline indistinct. He could only focus on one thing at a time, everything else would vanish, but now, as he says, he can see near and far. Also, at this time, objects had lost their weight. An ashtray, a cigarette, and a table all felt light, and when he lifted them there was no difference between them; but now "the table is heavy". Voices also, especially in the morning, were very loud and grated. This he exemplified by screwing up his face and putting his hands over his ears.

One month after operation the full scale I.Q., as estimated by the Wechsler-Bellevue test, had risen to 69, verbal I.Q. 70, performance I.Q. 73. The performance part of the test showed a gain of 10 points.
This test was carried out at the time when he still had the perceptual disturbance described above and is probably not a full guide to his intellectual improvement. Raven's Progressive Matrices were not done before operation, but when given nine weeks afterwards he obtained a score of 28, Grade IV-, which in this case corresponds closely to the Wechsler-Bellevue I.Q.
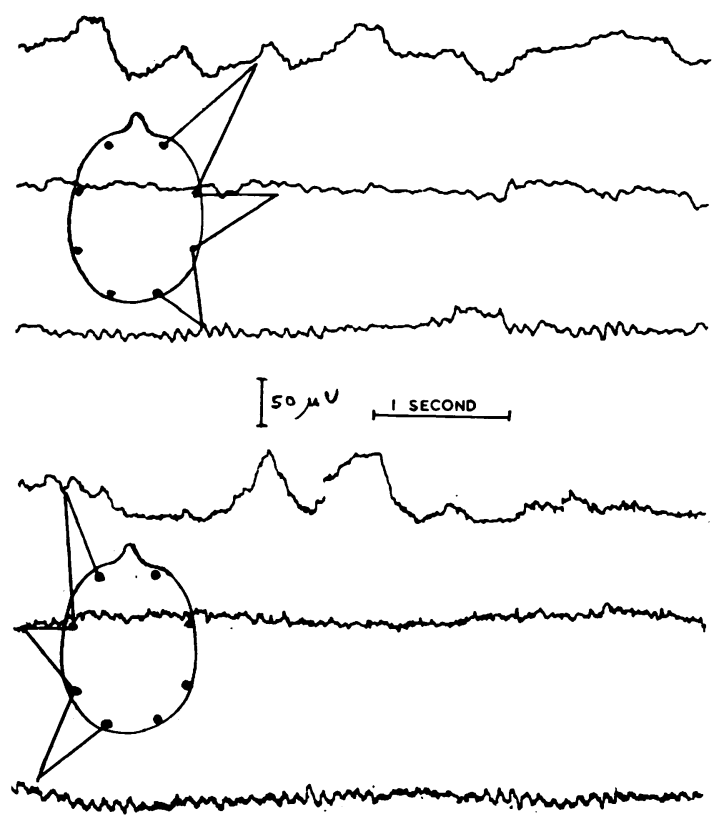

FIG. 10.-Case 2: one month post-operatively showing normal record with return of alpha rhythm.

\section{Discussion}

The clinical records of these two youths have much in common. Their birth and early years were normal, but after head injuries fits developed leading to a rapid deterioration in all spheres of behaviour. This deterioration eventually led to certification as mental defectives.

In both cases the fits were of the temporal lobe type, with well marked aura and not infrequent postepileptic automatism.

Their behaviour showed the most remarkable deviation from normal, especially in the second case. Both showed excessive " orality ", constantly demanding cigarettes and talking incessantly. They obtained great enjoyment from making simple quips, and the first patient constantly recited homemade childish rhymes. They were both extremely restless and meddlesome, interfering continually with other people's activities, and failed to learn from their rebuffs. In fact, H. G. R. often had to be separated from other patients for his own 
protection. This patient, in addition to the above symptoms, showed increased sexual activity as judged by masturbation. A peculiar form of oral recognition, in which objects, and especially people, were identified, was also present. The person's hand under review would be taken to the mouth. At no time did he ever attempt to bite. In addition, there was gross impairment of memory, for he was unable to recall post-operatively his previous two months' stay in this hospital. This was associated with perseveration of speech which commonly occurs in organic deterioration with loss of memory. This memory failure may be related to the frequently firing focus and secondary disorganization of the cortical electrical activity. The operation has resulted in an improvement of his ability to remember, for now he can recall events that have happened postoperatively. The perseveration of speech has also been abolished. After the return of normal recall he was able to describe a peculiar distortion of objects in which they appeared elongated and indistinct, and at the same time appeared to have lost their weight. It was impossible to determine how long this disturbance had been present because the loss of recent memory extended for an unknown period into his past. The perceptual distortion is of a type that occurs after mescaline intoxication. It is a most unusual response and is unlikely to be the result of a physical change in the brain as a result of surgery, because temporal lobectomy is frequently carried out for other lesions and this response has not been encountered before. It is most likely due to either a perceptual disturbance or based on lack of memory engrams by which judgment and comparisons are made. The latter cause is perhaps ruled out by the fact that he was able to conclude spontaneously that objects were now of normal dimensions and it is known that his memory up until at least 15 years of age was relatively intact, but more important still is the fact that he was able to name common objects correctly in spite of the distortion. It would seem therefore that it is a perceptual disturbance and this is apparently the basis of his peculiar inability to recognize people, except perhaps by oral sensations which are both physiologically and psychologically the earliest developed and probably form the most deeply entrenched engrams of all.

These symptoms are strongly reminiscent of the syndrome described by Klüver and Bucy (1939) which developed in monkeys subjected to bilateral anterior temporal lobectomy. These animals showed (1) "psychic blindness" in which they appeared unable to recognize objects on a visual basis alone ; (2) strong oral tendencies in which all objects were examined by mouth or nose ; (3) " hypermetamorphosis" which is used to describe a tendency for the monkeys to react to all objects as if under an "irresistible" impulse, thus showing an excessive tendency to react and take notice of everything in their visual field; (4) emotional changes in which the monkeys lose both their sense of fear and ready reaction to anger ; and (5) increased sexual activity.

Comparing the above symptoms with those present in our two patients, it will be seen that they are not dissimilar. However, an apparent paradox arises when it is realized that our patients exhibited the above symptomatology when the temporal lobes were intact, and their behaviour was relieved by the removal of a temporal lobe. This may be explained by the fact that the diseased lobe was frequently firing, especially in the second case, and caused the opposite lobe to fire synchronously and almost as frequently. As Jackson (1931b) pointed out: "Strong epileptic discharges paralyse the nervous centre (or much of it) in which they begin and through which they spread." Hence, this is equivalent to the functional loss of both temporal lobes. Besides the discharging foci, the electrical activity of the whole cortex was completely disorganized. It is more than probable that because of this the highest symbolic thinking by which man is distinguished from primates was so grossly disturbed that the ground for such a syndrome to develop was readily available. After operation the remaining lobe returned to a potentially normal state, as shown by the cortical electrical activity on the E.E.G., and so allowed normal behaviour to be established.

As a result of the operation both had monotonous voices with the loss of natural cadence, although in each case a lobe from a different side was removed and they were both right-handed. This monotonous voice was not due to lack of affect, for this was normal. In fact the monotony of speech was present when they were discussing interesting topics. It would seem to be a disturbance of an integral part of speech, or at least its development, for this disturbance has not been observed in adult patients whose fits started in later life. The natural cadence of the spoken word depends on the harmonious blending of the requisite idea and the emotion behind it. In these youths their emotional development was perhaps even more disturbed than their intelligence, and so this aspect of speech had a poor chance of developing.

In both cases temporal lobectomy of the more severely disturbed side has produced to date complete abolition of fits and a profound improvement in personality. Whether this will be permanent it 
is as yet too soon to say. However, it has given them a chance which would have been denied them without surgery.

\section{Summary}

Two cases of temporal lobe epilepsy, beginning in early life as a result of head injury, are described.

Attention is drawn to the associated disturbance in behaviour and its similarity to the Klüver and Bucy syndrome.

Temporal lobectomy was performed with amelioration of behaviour and a steady improvement in intelligence.

In one case, as a result of surgery, a maturational focus appeared in the E.E.G. and was associated with increased physical growth and emotional maturity.
As a result of surgery a monotonous voice developed and a possible explanation is offered.

We wish to thank Dr. R. M. Bates, Physician Superintendent of the Royal Eastern Counties Hospital, for referring the cases to us, and Dr. R. Ström-Olsen and Dr. D. Hill for helpful criticism.

\section{REFERENCES}

Gibbs, E. L., Gibbs, F. A., and Fuster, B. (1948). Arch. Neurol. Psychiat., Chicago, 60, 331

Gowers, W. R. (1892). A Manual of Diseases of the Nervous System,

2nd ed. Churchill, London.
Hill, D. (1952). Electroenceph. clin. Neurophysiol., 4, 419.

Jackson, J. H. (1931a). Selected Writings of John Hughlings Jackson. Vol. 1, p. 460. Hodder and Stoughton, London.

(1931b). Ibid. Vol. 1, p. 183.

Klüver, H., and Bucy, P. C. (1939). Arch. Neurol. Psychiat., Chicago, 42, 979.

Krynauw, R. A. (1950). Journal of Neurology, Neurosurgery and Psychiatry, 13, 243.

Penfield, W., and Erickson, T. C. (1941). Epilepsy and Cerebral Localization, p. 241 . Baillière, Tindall and Cox, London.

Poirier, L. J. (1952). J. comp. Neurol., 96, 209.

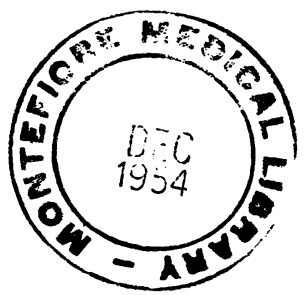

